\title{
Ectoplasm and Ectoplasm Fakers
}

\author{
The Other Side of the Psychic Picture, as Seen by a Skeptic \\ By James Black
}

\begin{abstract}
GPIRITISM seems to be as old as time; but the $S$ records are mainly of witcheraft and "black magic" until about the sixteenth century, when ghosts, specters and apparitions of a type similar to those of modern spiritism demand our attention. Early in the seventeenth century one Pierre le Loyer endeavored to formulate a science of specters. A little later reports of wonderful feats of levitation were current. For one of these Bishop Jeremy Taylor and iord Orrey were sponsors; and Dr. Joseph Glanvill, F. R. S., records cases of spirit rapping, among them the famous Tedworth Drummer and the Little Burton Ghost. In this superstitious age, however, organized critical investigation was not to be expected; and these cases are of significance to us only through the suggestive fact that they always involved a central figure-a medium-associated with the phenomena, and in whose absence peace usually prevailed.
\end{abstract}

For about a century and a half spiritism developed rapidly from these beginnings. The visiting spirits usually had an object in view-to solve a murder, to warn of death, in one case to collect a debt of 90 cents; and this accomplished, they usually withdrew. But the Cock Lane Ghost episode, of 1762 , provided a check to the growth of spiritism. One Kay invoked the law to collect a debt from his landlord Parsons; and a retaliatory spirit promptly accused Kay of having poisoned his wife. Many people of note were interested, including Goldsmith, Walpole and Samuel Johnson. Dr. Johnson proved beyond all doubt that Parsons' daughter Elizabeth made the rappings with a piece of wood, while her mother, a ventrilo-

quist, provided the spirit voices. The conviction and imprisonment of Parsons and his wife put spiritism under a cloud from which it emerged only in 1848 .

Modern spiritism really started with the exhibition of rapping given by the Fox Sisters at Rochester in 1849. The vogue spread, and soon they had many imitators. Their methods were exposed by several well accredited investigators, the late Dr. Carpenter for one. Daniel Douglas Home, next on the list, e s c a ped exposure doubtless through his utter refusal to be investigated, save on one occasion when

he failed to produce any phenomena while under test by the Dialectical Society of London. Levitation was his strong point. Much is made of the fact that Hom did not perform for money; but the court records will show that he was obliged to restore some $\$ 300,000$ which he had extorted from Mrs. Jane Lyon, a wealthy widow, whose husband "appeared" and instructed her to give up the money.

In spite of his complete failure to vindicate himsel before the court, Home was considered genuine by many prominent men, notably Sir D. Brewster and Rober Dale Owen. But Brewster, within one week, wrote two highly contradictory opinions, the one appearing in Home's Life and the other in Brewster's own, and this may fairly be taken as disqualifying him ; while Owen' incompetence as a judge is shown by the fact that in 1874 he reported the. Thomas Brothers as entirely genuine, only to see them later caught faking the very acts on which he had passed. Owen's style of investigation is well illustrated by his circumstantial account of a man who died after breakfast in Rhenish Prussia, and appeared in the spirit to a friend in New York, before noon on the same day-several hours before his demise, after correcting for the time difference. Al things considered, the court's opinion of Home is preferable to Brewster's or Owen's.

Other mediums followed in rapid succession, down to the notorious impostors Slade, Eglington and Palladino. Palladino is still cited as an exponent of true psychic phenomena, notwithstanding her exposures in Cambridge in 1895. and subsequently in New York. These exposures are calmly admitted, and the plea is advanced that when "her spirits failed her," he unxiety to produce results led her to resort to trickery. No explanation is offered for the facility with which she was always prepared for this necessity. The Rev. Stainton-Moses, an "amateur," is worthy special mention. He performed only before friends, and neither he nor his controlling spirit "Imperator" would brook investigation. His phenomena were, on their face, quite remarkable, but are, of course, utterly without confirmation. And his logic was very bad; he resigned from the Society for Psychic Research when that body was at pains to prove that many well-known mediums were carrying previous convictions for swindling. In fact, spirits and professional mediums were getting so much into disrepute at this time that Frederick Myers said "It does not seem worth while, as a rule, to examine the testimony on psychical marvels occurring in the presence of professional mediums." A very significant statement from such an authority, and as true today as it was then.

Spirit circles were troubled to account for many ghostly peculiarities and inconsistencies. The visiting spirit would occasionally be material enough for his light foot-falls to be heard, yet not sufliciently material for a brick wall or a closed door to bar his passage. The rapping spirit's visibility was in inverse ratio with his noise-making ability. These and other things led to the effort to account for the materialization on some new basis, that would make the discrepancies less damning. The fraud and deceit that had walked handin-hand with spiritism since its inception were a big handicap to the researchers, but obviously if they had real spirits these must be made of something. Some suggested a mysterious force, others an ethereal sub-

Franck Kluski, a medium, took wax casts of ectoplasmic hands and feet! Dr. Crawford's ectoplasm extruded from the lower part only of his medium's body and would strike sledge hammer blows on the floor, lift tables and several times poked him in the ribs so forcibly that he likened it to being poked with the blunt end of a metal rod. Geley has it luminous, and the action of light causes it to be reabsorbed instantly by the medium. But Crawford in all his 87 experiments never saw the plasma, and is at pains to prove that it is neither luminous, phosphorescent nor fluorescent. Crawford and Doyle agree that the mystery stuff instantly dissolves in light, yet both Geley and SchrenkNotzing have taken flashlight photographs of it.

The most alarming contradictions appear when the scientists come to the question of analysis. Geley states definitely that the plasma cannot be analyzed, for to detach a portion from the medium would "grievously harm and probably kill her. Then Schrenk-Notzing gives an analysis and the contents are reported as mainly cellular matter, such as is found in the mouth and throat. Stanley de Brathe, the translator of Geley's book, tells us that analysis shows the contents to be at least 50 per cent water, some sulfur and albumin, and gives the chemical formula as "something resembling" $\mathrm{C}_{120} \mathrm{H}_{1134} \mathrm{~N}_{218} \mathrm{~S}_{5} \mathrm{O}_{249}$. This formula will be quite familiar to a chemist-but he will not call it ectoplasm. Lebiedzinski-a Polish scientist-has ectoplasm analyses showing the contents as fats and human cellular matter, and the appearance like that of well-beaten white of egg. Then, presumably to clear up any confusion of opinion, Conan Doyle assures us that science knows absolutely nothing about ectoplasm, and improves on this statement by adding that analysis proves it to be composed of carbonates, phosphates and other matter unknown to anyone! A logical and scientific mind is absolutely unable to imagine such a mass of conflicting data passing under the name of scientific evidence. Try to imagine a substance that dissolves in light, yet does not do so; that can be analyzed, and cannot be analyzed; but when analyzed is found to consist of one assortment of elements, and also of several other very

stance; and the struggle to obtain harmony gave birth to a combination of the two theories and the present "ectoplasm" theory of spirit manifestations.

It will be in order to consider this theory, and the evidence in its favor, from a critical and judicial standpoint. Many reports of the remarkable nature of this substance are current, but little definite information is to be had. Vague generalities and the assurance that investigation has proved this to be a real and true phenomenon are not sufficient. To turn to the "scientists" who have done the investigating gives us interesting information, but involves us in hopeless contradiction.

All agree that ectoplasm is a plasma of psychic origin, extruding from the medium. Most add that it is the stuff of which perambulating spirits from the great beyond are made. It is unanimously possessed of some power or force that enables it to tip tables, rap floors, fabricate faces and limbs, and indulge in varied and remarkable phenomena. Here agreement ends; when our psychic friends endeavor to set out in scientific tyle the results of their research, and to state just what ectoplasm is and just what it does, it becomes plain that the investigations have been conducted in anything but a scientific manner; and any ordinary science student would be pardoned for considering that ectoplasm, in view of the nature of the evidence for it, is principally inflammation of the imagination.

Dr. Geley and Baron Schrenk-Notzing are the two most quoted authorities, with Ir. Crawford as a support. According to Dr. Geley, the plasma extrudes from the head of the medium in knobs, ribbons and fringes, of different colors; sometimes it is stiff and sometimes soft and elastic and at all times it shrinks from any contacts. Yet Geley, with the assistance of different assortments. That shrinks from all contacts but will throw tables and chairs around. That science knows nothing about; then promptly tells all about it! Sir Arthur Conan Doyle recently stated that scientists and psychic researchers were "scandalously skeptical" about ectoplasm. us credulity?

Dr. Geley and Baron Schrenk-Notzing used the same medium in their research work, this medium being known as Eva Cariere. As the results of the research are being offered as a contribution to scientific knowledge, it is natural to look for a medium of unimpeachable integrity and for indications of the methods of science in the details of the researchers. Unfortunately we look in vain. Geley assures us that there was no possibility of trickery on the part of the medium, but he fails to mention any adequate precautionary measures that were adopted. When Schrenk-Notzing makes some attempt to guard against fraudulent methods the results indicate quite clearly that fraud was not only possible, but highly probable.

Dr. Geley's investigations took place in darkness. The medium took her place in a cabinet and went into a trance. Extrudations of the plasma began and were built up into spirit hands, faces and sometimes heads complete, topped with real hair through which Dr. Geley ran his fingers-forgetting for the moment that the plasma must not be touched. The heads and faces always appeared in the vicinity of the medium, in no case more than 27 inches from the cabinet-just about arm's length. The development of the plasma took place behind the curtain of the cabinet. The partly formed head or face would suddenly appear in an opening of the curtain, disappear and then reappear (Continued on page 215) 
Ectoplasm and Ectoplasm Fakers and seated unfettered on a chair, she pro\begin{tabular}{l|l} 
(Continued from page 162) & duced the usual spirit heads, faces, voices \\
and lights; all in the immediate vicinity of
\end{tabular} in a short time in a further state of de- where her hands and head were likely to be. velopment. The same thing happened in Then when her hands were shackled she reverse on dematerialization. Too much hap- still produced phenomena, but in a more that Dr. Geley did not hold on to the hair other test the possibility of fraud was furhe had his fingers in; he might have found ther narrowed by inclosing her in a cabinet Eva in the neighborhood. Baron Schrenk-Notzing's experiments results were very disappointing: few phewere conducted in a similar manner to nomena appeared, and the spirit lights could Geley's, and showed like phenomena. On not get more than an inch or so from the one occasion when Eva was searched before net. Next seance the medium was searched entering the cabinet there was a marked thoroughly and placed in a cabinet which diminution of phenomena, both in kind and had been searched also. The results were degree. Two spirit faces, phosphorescent in negative: thorough investigation killed these appearance, were seen hovering near the as other spirits.

cabinet, and a small blob of ectoplasm on
con the final seance, however, really wonthe lips of the medium. One of the ob- derful things happened. Miss Bessinet was servers took a flashlight photograph of the not searched, wore her own clothes, and no faces and on development the plates showed effort was made to prevent her indulging them to be photographs of two well-known in fraud. One of her controlling spirits men, touched up with luminous paint to give kindly tied her to a chair and she drifted the spirit-like effect.

The British Society for Psychic Research and faces were in evidence, and roamed much invited Eva Cariere to London to demon- farther than the medium could do, as she strate her mediumship. At a seance under was tied to the chair. After a time one of the auspices of the society Eva was subjected the spirit faces, wonderfully clear and rato searching tests, and rigid conditions. Be- $\begin{aligned} & \text { diant with an ectoplasmic light, slowly ap- } \\ & \text { proached the table at which the investigators }\end{aligned}$ searched, and the cabinet was also thorough- were sitting, and seemed to be hovering in searched, and the cabinet was also thorough-
ly investigated. Nothing of a contraband
the darkness quite close to one of them. This nature was found. Eva went into a trance was considered a suitable time for a close nature was found. Lva went into a trance
and produced-absolutely nothing, neither heads, faces nor ectoplasm! Eva blamed light. Once more Geley's absorbing and the London atmosphere! It seems pretty Crawford's dissolving theory regarding ectowell established that if Eva takes no "props"
into the cabinet nothing out of the ordinary into the cabinet nothing out of the ordinary
happens. Briefly stated-no search, spooks; as the very material Bessinet herself, her

With such strong presumptive evidence of fraud on the records, and as no psychic researcher can be more reliable on well to look into Evia Cariere's record. As far as can be ascertained she was born in for some years practiced there and in Algeria as a clairvoyant and medium under that name. She finally attracted considerable
attention by means of many. demonstrations attention by means of many. demonstrations
new and extraordinary, especially her exnew and extraordinary, especially her ex-
trudations of ectoplasm. Eugene Marsaut, a French notary and member of the French Society for Psychical Research, decided to investigate her. He made no effort to prevent fraudulent methods being adopted by
the medium if she so desired, but during the manifestations he turned a flashlight on the operations and Marthe was caught redhanded. Her spirit faces were just "props," her ectoplasm nothing more supernatural of regurgitated albuminoid matter. M. Marsaut obtained a signed confession that ${ }^{\circ}$ her festations was produced by fraudulent means,

and a record of the frauds and exposure is to be found fully set forth in the proceedings of his society.

Marthe Beraud's debacle occurred in 1914 She returned to France, laid low for a time, then came forth from her retirement under lier present name, to fool all and sundry down to date. Such is the story of the me-
clium, on whose manifestations and integrity the scientific evidence of Geley and others in favor of the reality of ectoplasmic manifestations rests itself. Preserve us from such science!

There are other notable producers of this ectoplasm. Einer Neilson created a stir in until the Norwegian Society Psychical Research investigated his claims. culiar to spiritism, are adopted. In place of the At a seance under the observation of mem- $\begin{aligned} & \text { desire to make an open-minded search for the } \\ & \text { truth we see an absolute determination to get }\end{aligned}$ appeared, but one of the investigators had psychic results and verify the spiritistic no fear of the dangers of ectoplasm, so dur- claims.

ing the extrudation took a chance on it dis- There is too much of the "hole and corsolving or being reabsorbed. He turned a ner" method in the psychist's investigations flashlight on the medium. The investigation too much darkness, and a disregard for inshowed that the ectoplasm of Neilson was telligent investigation that places the whole $_{\text {the }}$ showed that the ectoplasm of Neilson was
nothing more than shreds of silk gauze which
business in a ridiculous position when viewed nothing more than shreds of silk gauze which business in a ridiculous position when viewed The records of the society afford proof of dence. Careful consideration of the evidence the fraud of the ectoplasm investigated upon $\mid \begin{aligned} & \text { dence. } \\ & \text { for and against the reality and truth of ecto- }\end{aligned}$ this occasion.

his occasion.

Another medium of wonderful power and attainment is Ada Bessinet, of Toledo, Ohio,
who produces practically every phenomenon known to psychic science - spirit faces, voices, levitations and so forth. The means she employs are "ectoplasmic soul exteriorizations," which no doubt is quite all right -if you know what it means. The British Coltege of Psychic Science arranged a series
of seances under the direction of Mr. J. H. Mackenzie, the principal of the college. Miss Bessinet ic a very sensitive medium, and can the whole fre wulent business in wo keeps produce her phenomena in absolute darkness the evidence, for there is none that can withonly. In one seance, not being searched, $\mid$ stand critical analysis.

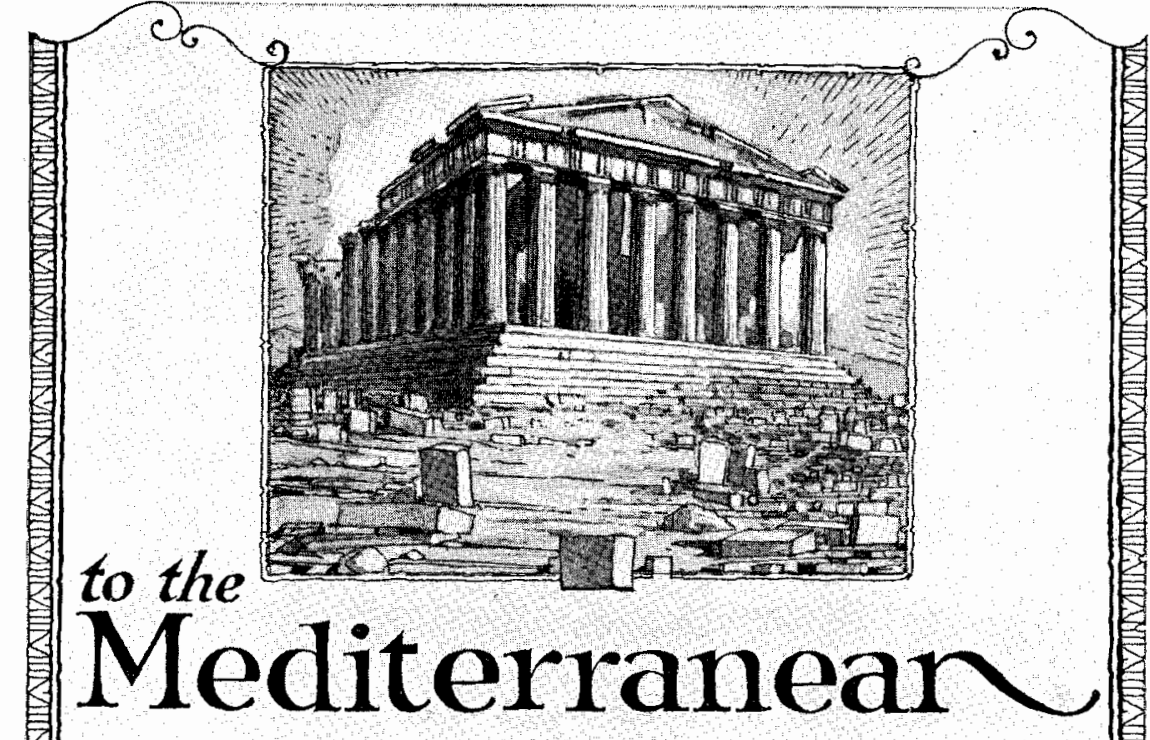

\section{AN EXCEPTIONAL OPPORTUNITY}

Special Fall and Winter Sailings

from New York by

TUSCANLA * Oct. 26, Dec. 6

SCYTHIA - November 25

CARONIA - February 10

To Madeira, Gibraltar, Algiers, Monaco (Riviera), Genoa, Naples Alexandria (Cairo)

*Tuscania also calls at Vigo

Stop-overs and return trips via North Atlantic may be arranged.

\section{U N A R D and ANCHOR Lines}

25 Broadway, New York or Branches and Agencies

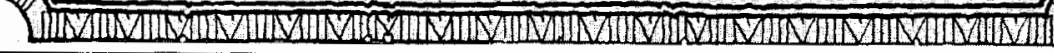

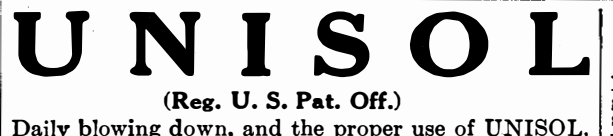

MR. INVENTOR

Daily blowing down, and the proper use of UNISOL
gradually removes boiler scale, prevents scale formation, stops and prevents corrosion and pitting, a
removes grease from steam boilers.

amphlet on request. Money back guarant
UNISOL MFG. CO.. Jersey City, N. J.

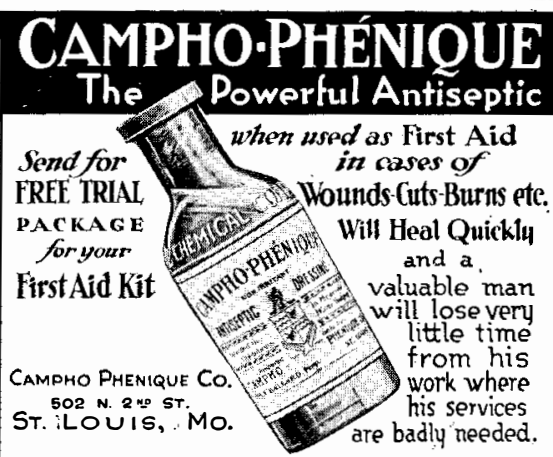

FOR YOUR FIRST AID KIT

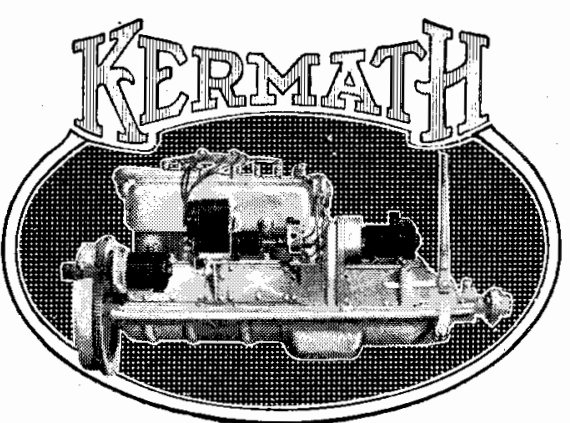

MARINE ENGINES

Our 4 cylinder, 4 cycle, electrically equipped enor 28 to 32 foot cruiser

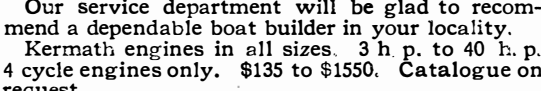

Ask us about our special guarantee

"A Kermath Always Runs"'

Kermath Manufacturing Company
5880 Commonwealth Ave. Dept. N Detroit, Mich.

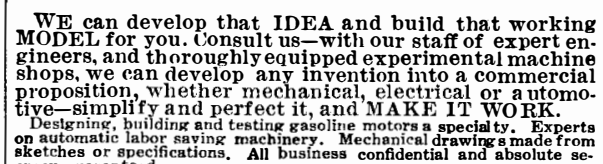

crecy guaranteed.
1926 B Brom MFG. Co., Ine.

\section{A STEELOMETER}

An instrument that wil prove of great assistance to the hardener of any tool steel as it indicates the exact heat for hardening.

One of our customers write us: "We can
not praise the Steelometer too highly."

Price $\$ 7.00$ sent parcel post. Send for descriptive matter.

THE STEELOMETER CO. GLEN RIDGE, NEW JERSEY Agents Wanted

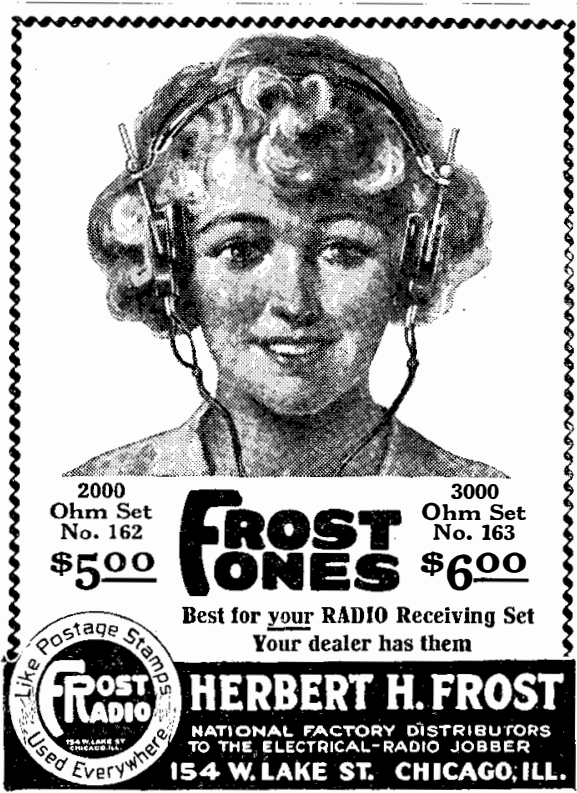

